Proc. Indian Acad. Sci. (Earth Planet. Sci.), Vol. 98, No. 3, October 1989, pp. 255-263.

C) Printed in India.

\title{
Canonical sound speed profile for the Central Bay of Bengal
}

\author{
T V RAMANA MURTY ${ }^{\dagger}$, S PRASANNA KUMAR, \\ Y K SOMAYAJULU, J S SASTRY and RUI J P DE FIGUEIREDO* \\ National Institute of Oceanography, Dona Paula, Goa 403004 , India \\ * Departments of Electrical and Computer Engineering and Department of Mathematical \\ Sciences, Rice University, Houston, Texas 77251, USA
}

MS received 20 January 1989; revised 31 August 1989

\begin{abstract}
Following Munk's canonical theory, an algorithm has been presented for computing sound channel parameters in the western and southern Bay of Bengal. The estimated canonical sound speed profile using these parameters has been compared with computed values for a set of CTD and hydrocast data. The analysis indicates appreciable variation in the perturbation coefficient $\varepsilon$ even over short ranges, particularly in the eastern region. This has an important implication in ray tracing, where the range dependency of the acoustic field can be introduced with suitable modification. In the region where the channe! axis is nearly symmetrical about the upper and lower bound, the canonical profte almosi reproduces the computed one. The results of the exponential, stratified model lead to a reasonable realistic fit with the ocean beneath the thermocline.
\end{abstract}

Keywords. Tomography; canonical; sound channel; stratification scale; perturbation coefficient.

\section{Introduction}

Ocean acoustic tomography, as a feasible technique, has been accepted for monitoring mesoscale variations in the oceans (Munk and Wunsch 1979). This utilizes the knowledge of sound-speed field and its variability, along with the ray path geometry and ray arrival structure within the ocean. While the former has been studied earlier (Prasanna Kumar et al 1988) wherein the sound-speed field has been represented by two high energetic modes (the first mode being a numerical mean profile) the latter could be achieved through simulation studies for a given source-receiver configuration (Somayajulu et al 1985).

For simulation studies a parametric representation of the sound-speed profile is needed (Jones et al 1985). In the present study, we construct a representative soundspeed profile for the Central Bay of Bengal (figure 1) in an analytical form following Munk's theory (Ramana Murty et al 1987). This theory enables us to present the sound-speed profile at any geographical location with the help of a few parameters obtained from hydrographic data, apart from its implication in ray tracing.

\footnotetext{
t To whom correspondence should be addressed.
} 


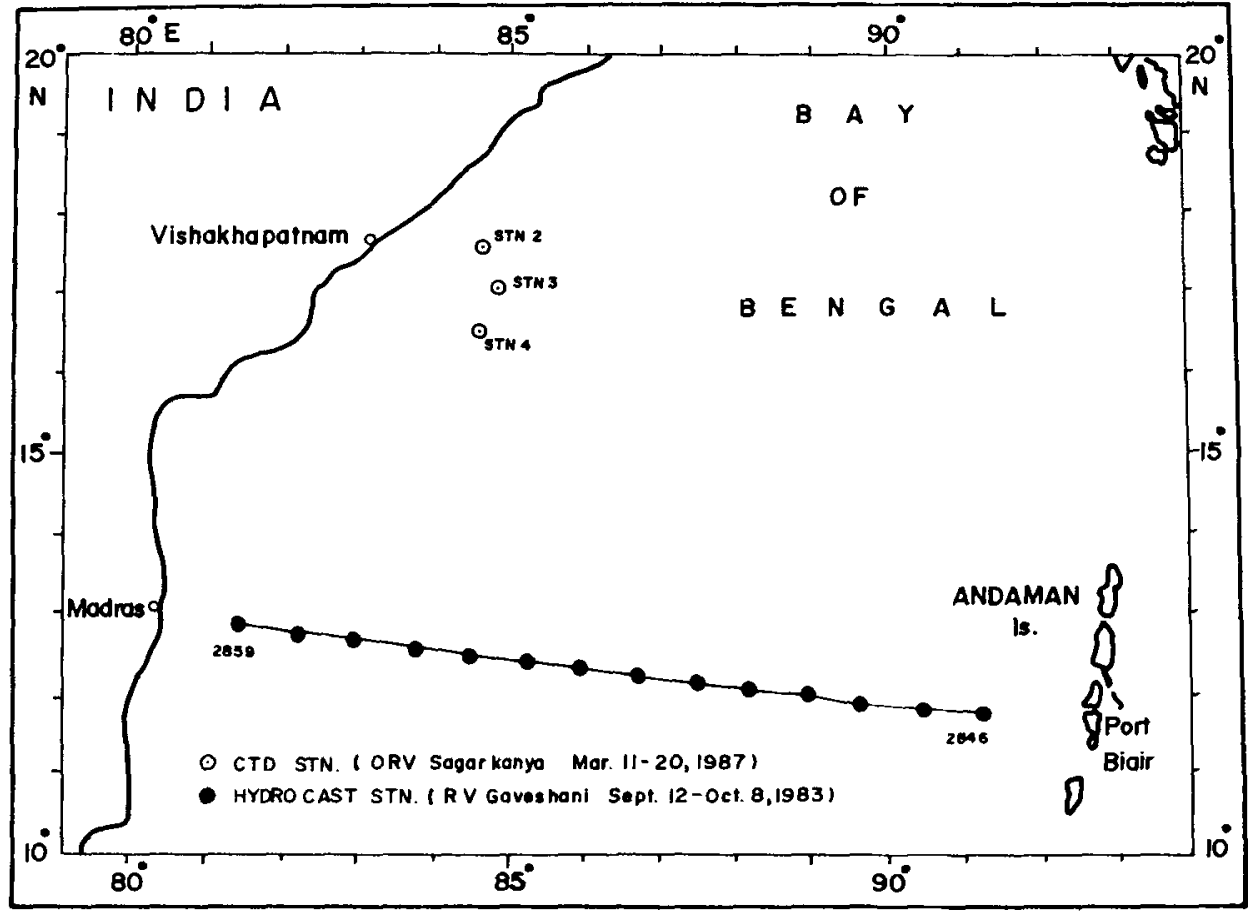

Figure 1. Location of CTD and hydrocast stations.

\section{Materials and methods}

The canonical expression for the sound-speed profile (Munk 1974) is

$$
C(Z)=C_{1}\left[1+\varepsilon\left(\eta+e^{-\eta}-1\right)\right]
$$

where $\eta=2\left(Z-Z_{1}\right) / B$ is the dimensionless distance above sound channel axis, $B$ the stratification scale and $\varepsilon$ the perturbation coefficient. After obtaining the coefficients $a$ and $b$, (Appendix A) the sound-speed may be computed from the above expression (1). The computational procedure is given in Appendix A.

To assess the suitability of the canonical sound-speed profile, a typical set of hydrographic data from the Bay of Benal were obtained by discrete (hydrocast) and continuous sampling (figure 1). These data sets were subjected to cubic spline (for continuous data) and weighted parabolic (for discrete data) interpolation (Reininger and Ros 1968) to obtain observations at closely spaced depth (10 m) intervals. From these data, the sound-speed has been computed following Chen and Millerio (1977) to obtain the sound speed at the channel axis $\left(C_{1}\right)$ and the depth of the channel axis $\left(Z_{1}\right)$. The next step was to determine the upper and lower bounds of integration $(-\alpha, \beta)$ for the integrals appearing in Appendix A for computation of the stratification scale $B$ and perturbation coefficient $\varepsilon$ (figure 3). This is explained in the next section. 


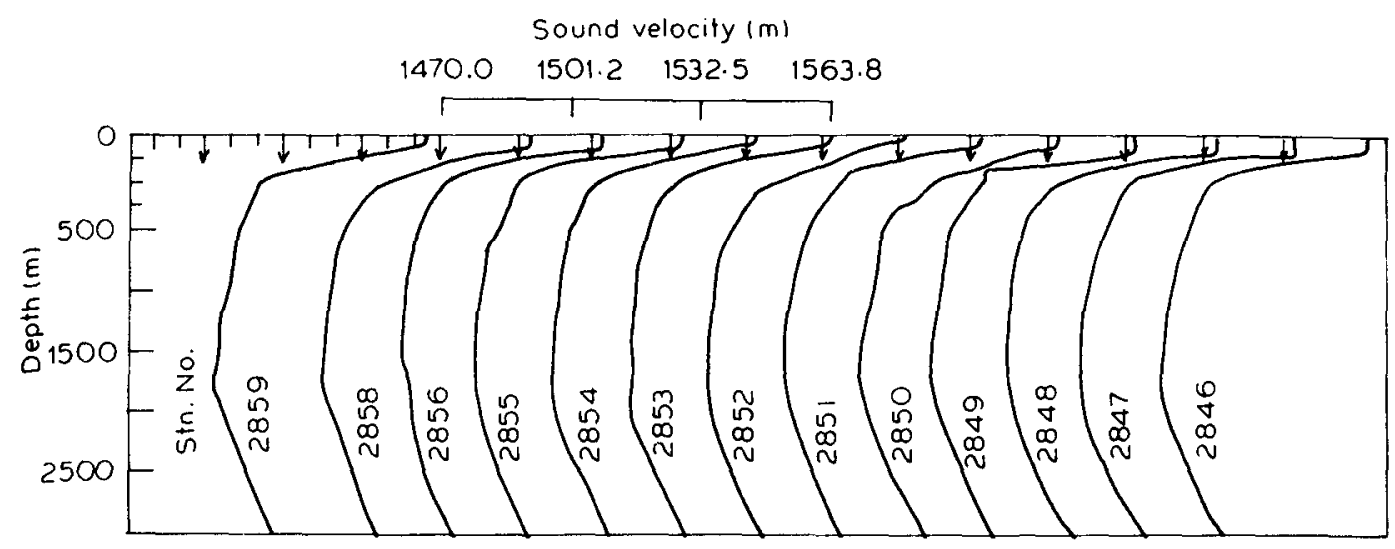

Figure 2. Sound-speed profiles along the transect shown in figure 1.

Oceon surface

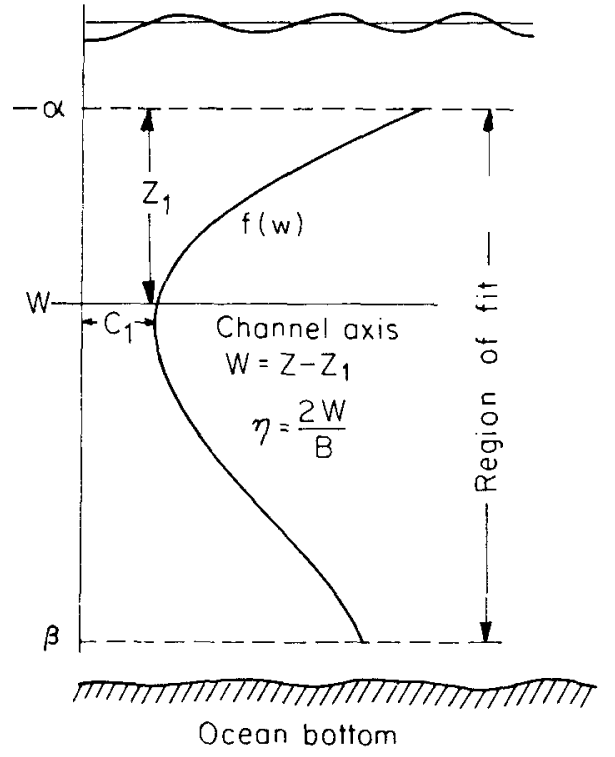

Figure 3. Schematic representation of sound- speed profile.

\section{Results and discussion}

In the Bay of Bengal the speed of sound is higher at the surface than at the bottom (figure 2). This indicates an effective acoustic wave guide lying below depths of 140 to $250 \mathrm{~m}$ (solely due to depth limitations). For this reason, the upper bound has been tentatively chosen at $250 \mathrm{~m}$ for computational convenience. The Central Bay of Bengal has an average depth of $3 \mathrm{~km}$. This depth has been taken as the lower bound. The sound channel model parameters used for computation of the speed of sound are shown in table 1 . The values of $\alpha$ and $\beta$ shown in this table were computed as explained in Appendix A. To understand how closely the canonical profile follows the values computed from hydrographic data, plots of departures with depth at each of 
Table 1. Canonical sound channel model parameters.

\begin{tabular}{|c|c|c|c|c|c|c|}
\hline & $\begin{array}{c}\alpha \\
(\mathrm{m})\end{array}$ & $\begin{array}{c}\beta \\
(\mathrm{m})\end{array}$ & $\begin{array}{l}Z_{1} \\
(\mathrm{~m})\end{array}$ & $\begin{array}{c}C_{1} \\
(\mathrm{~m} / \mathrm{s})\end{array}$ & $\begin{array}{c}B \\
(\mathrm{~km})\end{array}$ & $\begin{array}{c}\varepsilon \\
\times 10^{-3}\end{array}$ \\
\hline \multicolumn{7}{|c|}{ CTD data } \\
\hline Stn. 2 & 250 & 2490 & 1490 & $1493 \cdot 72$ & $1 \cdot 4148339$ & $6 \cdot 27009$ \\
\hline Stn. 3 & 250 & 2490 & 1480 & $1493 \cdot 36$ & $1 \cdot 4144729$ & $7 \cdot 70402$ \\
\hline Stn. 4 & 250 & 2490 & 1460 & $1493 \cdot 50$ & 1.4152324 & $7 \cdot 36964$ \\
\hline \multicolumn{7}{|c|}{ Hydrocast data } \\
\hline \#2859 & 250 & 3000 & 1660 & 1492.42 & 1.7100943 & $8 \cdot 26990$ \\
\hline \# 2858 & 250 & 3000 & 1580 & $1493 \cdot 37$ & $1 \cdot 7285531$ & 6.53254 \\
\hline \#2856 & 250 & 3000 & 1490 & $1492 \cdot 38$ & 1.7367017 & $6 \cdot 69301$ \\
\hline \# 2855 & 250 & 3000 & 1670 & 1492.09 & 1.7217247 & 7.00319 \\
\hline \#2854 & 250 & 3000 & 1690 & $1492 \cdot 29$ & $1 \cdot 7214069$ & $7 \cdot 18058$ \\
\hline \#2853 & 250 & 3000 & 1500 & $1491 \cdot 60$ & 1.7343166 & $7 \cdot 52465$ \\
\hline \#2852 & 250 & 3000 & 1450 & $1492 \cdot 61$ & 1.7359395 & $7 \cdot 14998$ \\
\hline \#2851 & 250 & 3000 & 1470 & $1492 \cdot 21$ & $1 \cdot 7342341$ & $7 \cdot 76116$ \\
\hline \#2850 & 250 & 3000 & 1660 & 1491.98 & 1.7178526 & $9 \cdot 13943$ \\
\hline \#2849 & 250 & 3000 & 1600 & $1491 \cdot 64$ & 1.7251973 & $7 \cdot 96145$ \\
\hline \#2848 & 250 & 3000 & 1500 & 1495.03 & 1.7506714 & $3 \cdot 44785$ \\
\hline$\# 2847$ & 250 & 3000 & 1320 & $1490 \cdot 87$ & 1.7510667 & 7.65039 \\
\hline$\# 2846$ & 250 & 3000 & 1590 & 1491.62 & $1 \cdot 7252729$ & $8 \cdot 61798$ \\
\hline \multicolumn{7}{|c|}{ Mean values for the above hydrocast data } \\
\hline & 250 & 3000 & 1490 & $1492 \cdot 10$ & $1 \cdot 7344670$ & $7 \cdot 3407460$ \\
\hline
\end{tabular}

the stations were made. It can be seen that the canonical profile closely follows the sound speed profile computed from hydrographic data, though there are some departures at the top layer. The deviations are presented in terms of a percentage in tables 2, 3 and 4 for CTD data, while for hydrocast data the typical patterns are presented in figure 4 . It is evident from the tables as well as from the figure that the percentage deviation is a maximum at the upper bound $(250 \mathrm{~m})$ and with an increase in depth the error decreases rapidly towards the channel axis. However, below the channel axis $Z_{1}$, the error is very small and is confined to a maximum value of $0.2 \%$. Based on the data along the transect of figure 1, the sound-speed profiles were averaged (figure $4 \mathrm{~b}$ ) and a model profile was developed. One observes that at the upper and lower bounds, the departures are $8 \mathrm{~m} / \mathrm{s}$ and $4 \mathrm{~m} / \mathrm{s}$ respectively, indicating a best fit. However, these small departures of the canonical sound-speed from the computed sound-speed in the upper layer is less likely to affect acoustic rays with low emergence angle, as their path will be confined to the deeper layers of the SOFAR (sound fixing and ranging) channel only. But the steep angle rays which undergo near-surface refraction, may, to a certain extent, be affected by these deviations. This need not introduce serious errors while inferring the gross features of the media, because the path lengths of steep angle rays are very small near the surface (compared to deeper layers) due to high gradients $(0.1 \mathrm{~m} / \mathrm{s}$ per meter at $250 \mathrm{~m}$ compared to $0.06 \mathrm{~m} / \mathrm{s}$ per meter at $3000 \mathrm{~m}$ ).

The special variation of the perturbation coefficient, stratification scale and depth of sound channel axis from the western Bay to the eastern Bay is shown in figure 5 . The spatial trends of $B$ and $Z_{1}$ are the same. The variation of perturbation coefficient, 
Table 2. Comparison of canonical fit with computed sound-speed profile at $\operatorname{Stn} .2$.

\begin{tabular}{|c|c|c|c|c|c|}
\hline $\begin{array}{l}\text { Depth } \\
Z \\
(\mathbf{k m})\end{array}$ & $\begin{array}{c}\left(Z-Z_{1}\right) \\
(\mathrm{km})\end{array}$ & $\begin{array}{c}\text { Canonical } \\
\text { sound-speed } \\
(\mathrm{km} / \mathrm{s})\end{array}$ & $\begin{array}{c}\text { Sound-speed } \\
\text { computed } \\
\text { from } \\
\text { hydrographic data } \\
(\mathrm{km} / \mathrm{s})\end{array}$ & Deviation & $\begin{array}{c}\text { Percentage } \\
\text { deviation }\end{array}$ \\
\hline $0 \cdot 25$ & $-1 \cdot 24$ & 1.521989 & $1 \cdot 503570$ & 0.018 & 1.225 \\
\hline 0.50 & -0.99 & $1 \cdot 509206$ & $1 \cdot 498440$ & 0.011 & 0.719 \\
\hline 0.75 & -0.74 & $1 \cdot 501216$ & 1.496620 & 0.005 & 0.307 \\
\hline 1.00 & -0.49 & 1.496589 & 1.494720 & 0.002 & 0.125 \\
\hline $1 \cdot 25$ & -0.24 & 1.494325 & 1.493960 & 0.000 & 0.024 \\
\hline 1.50 & $0-01$ & 1.493721 & 1.493790 & $0-000$ & 0.005 \\
\hline 1.75 & 0.26 & 1.494282 & 1.493390 & 0.001 & 0.060 \\
\hline 2.00 & 0.51 & 1.495661 & $1 \cdot 494810$ & 0.001 & 0.057 \\
\hline $2 \cdot 25$ & 0.76 & 1.497615 & 1.496980 & 0.001 & 0.042 \\
\hline $2 \cdot 49$ & 1.00 & $1 \cdot 499872$ & 1.499870 & 0.001 & 0.067 \\
\hline
\end{tabular}

Table 3. Comparison of canonical fit with computed sound-speed profile at Stn. 3.

\begin{tabular}{lccccc}
\hline Depth & \multicolumn{5}{c}{$\begin{array}{c}\text { Sound-speed } \\
\text { computed } \\
\text { from }\end{array}$} \\
$(\mathbf{k m})$ & $\begin{array}{c}\text { Canonical } \\
\left(\mathbf{k}-Z_{1}\right)\end{array}$ & $\begin{array}{c}\text { sound-speed } \\
(\mathbf{k m} / \mathrm{s})\end{array}$ & $\begin{array}{c}\text { hydrographic data } \\
(\mathrm{km} / \mathrm{s})\end{array}$ & Deviation & $\begin{array}{c}\text { Percentage } \\
\text { deviation }\end{array}$ \\
\hline 0.25 & -1.23 & 1.527338 & 1.507360 & 0.020 & 1.325 \\
0.50 & -0.98 & 1.511904 & 1.498940 & 0.013 & 0.865 \\
0.75 & -0.73 & 1.502276 & 1.496740 & 0.006 & 0.370 \\
1.00 & -0.48 & 1.496726 & 1.494720 & 0.002 & 0.134 \\
1.25 & -0.23 & 1.494040 & 1.493880 & 0.000 & 0.011 \\
1.50 & 0.02 & 1.493364 & 1.493440 & 0.000 & 0.005 \\
1.75 & 0.27 & 1.494101 & 1.493400 & 0.001 & 0.047 \\
2.00 & 0.50 & 1.495829 & 1.494530 & 0.001 & 0.087 \\
2.25 & 0.77 & 1.498254 & 1.496950 & 0.001 & 0.087 \\
2.45 & 0.97 & 1.500402 & 1.499010 & 0.002 & 0.102 \\
\hline
\end{tabular}

Table 4. Comparison of canonical fit with computed sound-speed profile at Stn. 4.

\begin{tabular}{|c|c|c|c|c|c|}
\hline $\begin{array}{l}\text { Depth } \\
Z \\
(\mathrm{~km})\end{array}$ & $\begin{array}{c}\left(Z-Z_{1}\right) \\
(\mathrm{km})\end{array}$ & $\begin{array}{c}\text { Canonical } \\
\text { sound-speed } \\
(\mathrm{km} / \mathrm{s})\end{array}$ & $\begin{array}{c}\text { Sound-speed } \\
\text { computed } \\
\text { from } \\
\text { hydrographic data } \\
(\mathrm{km} / \mathrm{s})\end{array}$ & Deviation & $\begin{array}{c}\text { Percentage } \\
\text { deviation }\end{array}$ \\
\hline 0.25 & -1.21 & $1 \cdot 524385$ & $1 \cdot 507560$ & 0.017 & $1 \cdot 116$ \\
\hline 0.50 & -0.96 & $1 \cdot 510245$ & 1.499100 & 0.011 & 0.743 \\
\hline 0.75 & -0.71 & 1.501450 & 1.496640 & 0.005 & 0.321 \\
\hline 1.00 & -0.46 & 1.496419 & 1.494580 & 0.002 & 0.123 \\
\hline 1.25 & -0.21 & 1.494036 & 1.493850 & 0.000 & 0.012 \\
\hline $1 \cdot 50$ & 0.04 & 1.493517 & 1.493550 & 0.000 & 0.002 \\
\hline 1.75 & 0.29 & 1.494310 & 1.492190 & 0.002 & $0 \cdot 142$ \\
\hline $2 \cdot 00$ & 0.54 & $1 \cdot 496027$ & 1.494250 & 0.002 & 0.119 \\
\hline $2 \cdot 25$ & 0.79 & 1.498394 & 1.497100 & 0.001 & 0.086 \\
\hline 2.49 & 1.03 & 1.501099 & $1 \cdot 500090$ & 0.001 & 0.167 \\
\hline
\end{tabular}




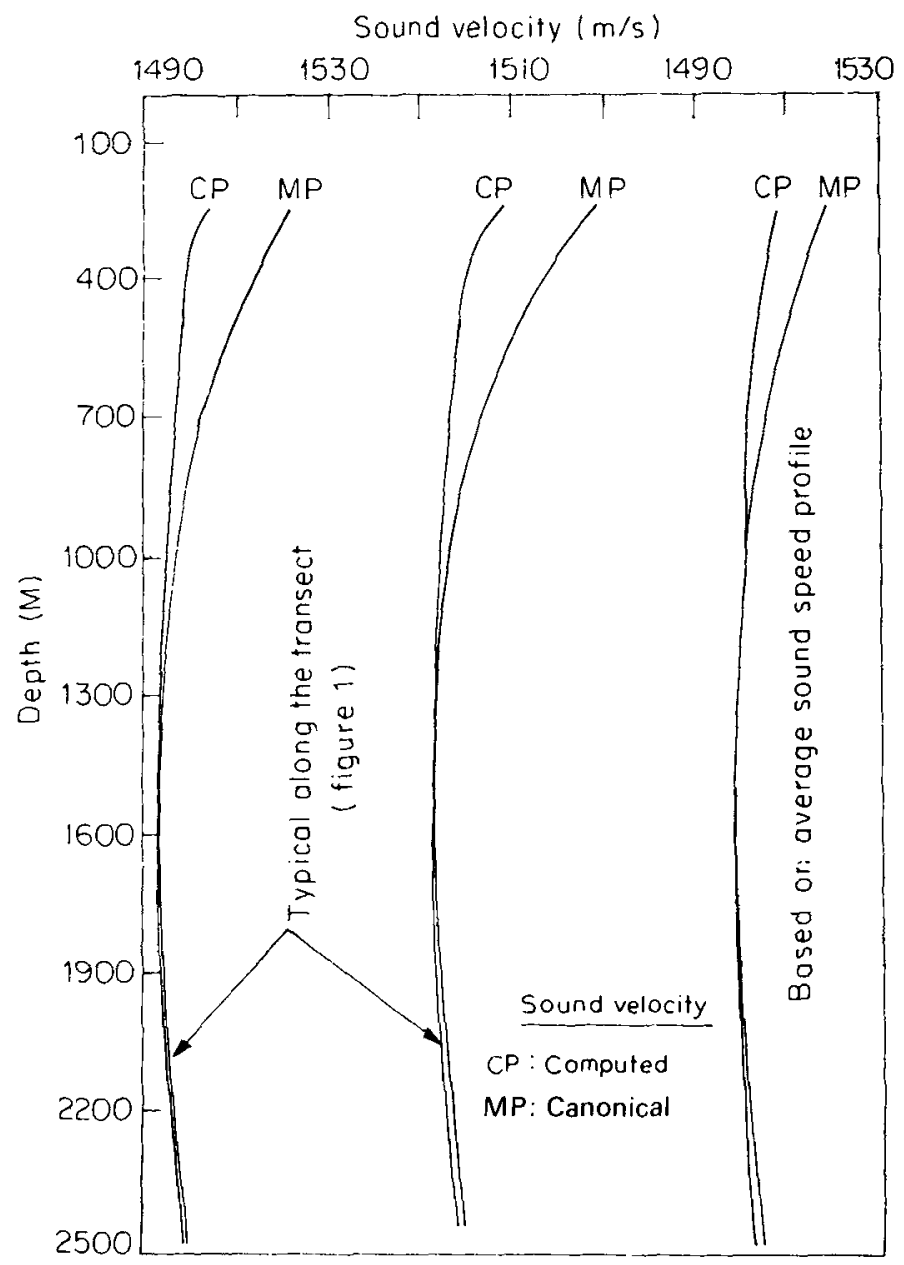

Figure 4. Comparison of canonical sound-speed profile (MP) with computed (CP) profile for hydrocast data.

which is interpreted as the fractional adiabatic velocity increase over scale depth (Munk 1974), in the western part of the Bay is small (ranging from 6.5 to $7.5 \times 10^{-3}$ ). It shows a gradual increase from the west to the east. However, in the eastern Bay it varies considerably, indicating the highly variable nature of the sound-speed field in this part. This was reported earlier (Prasanna Kumar et al 1988). The appreciable variation in $\varepsilon$ and $B$ in this area (between 800 and $1000 \mathrm{~km}$ ) indicates the range dependency of the sound-speed field. This allows one to introduce the range dependency by suitably modifying the perturbation coefficient, which is needed for realistic numerical ray-tracing to accurately predict the arrival sequence of the acoustic signals.

From this study it is evident that the exponential stratification model gives a reasonable fit to the ocean beneath the thermocline. For the simulation studies from the derived analytical form of the profile, one can proceed to higher order derivatives in a closed form for ray computation and intensity calculations. But very close to the region of the thermocline, the observed variability in $B$ and $\varepsilon$ indicates the inadequacy 


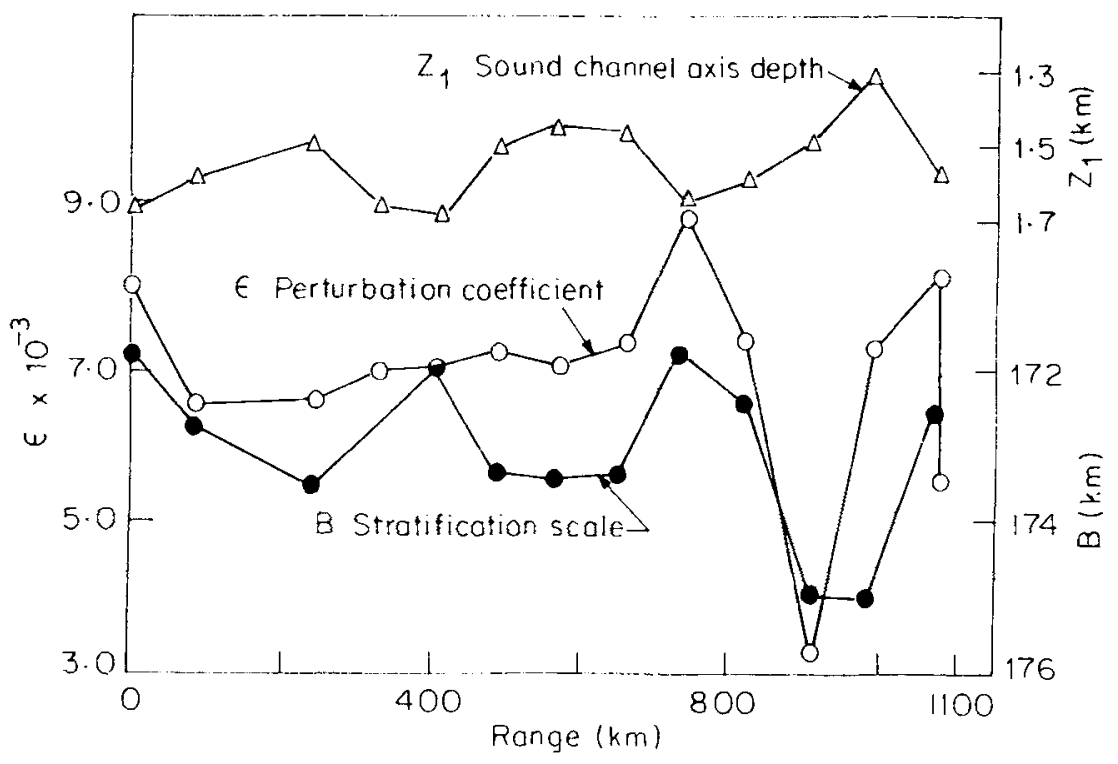

Figure 5. Spatial distribution of perturbation coefficient $\varepsilon$, stratification scale $B$ and depth of the sound channel axis $Z_{1}$ along the track.

of the canonical profile in reproducing the sound-speed profile to the expected level. The reason for this could be the large scale wind forcings, and the considerable quantities of fresh waters discharged during the south west monsoon. Incidentally, recent studies by Munk and Wunsch (1987) pointed out the difficulty in reproducing the sound-speed profile by an analytical form when seen against the computed profile (from temperature, salinity and pressure) and other model profiles.

\section{Acknowledgements}

The authors thank Dr C S Murty and Dr D Srinivasan of IIT Madras for useful discussions. They also acknowledge the financial assistance from the Department of Ocean Development, New Delhi in the form of a grant.

\section{Appendix A}

The canonical expression for the sound velocity profile (Munk 1974) in terms of a dimensionless distance above the sound channel axis is

$$
C(Z)=C_{1}\left[1+\varepsilon\left(\eta+e^{-\eta}-1\right)\right],
$$

where the dimensionless distance above the channel axis $Z_{1}$ is

By writing

$$
\eta=2\left(Z-Z_{1}\right) / B
$$

$$
W=Z-Z_{1}
$$


we have

$$
C(Z)=C\left(W+Z_{1}\right)=\tilde{C}(W)
$$

By expanding the exponential, the non-dimensional form of (A.1) is

$$
\frac{\widetilde{C}(W)}{C_{1}} \cong 1+2\left(\varepsilon / B^{2}\right) W^{2}-\frac{4}{3}\left(\varepsilon / B^{3}\right) W^{3}
$$

Designating $\varepsilon / B^{2}=a$ and $\varepsilon / B^{3}=b$, we find (A.2) can be rewritten as

$$
\hat{f}(W) \equiv \frac{\tilde{C}(W)}{C_{1}}=1+2 a W^{2}-\frac{4}{3} b W^{3} .
$$

The parameters $a$ and $b$ can be obtained by fitting the measured $f(W)$ to the expression in (A.3) by least squares.

Define the error as

$$
J(a, b)=\int_{-\alpha}^{\beta}\left[f(W)-1-2 a W^{2}+\frac{4}{3} b W^{3}\right]^{2} \mathrm{~d} W
$$

and use the condition

$$
\begin{aligned}
& \frac{\partial J}{\partial a}(a, b)=0, \quad \frac{\partial J}{\partial b}(a, b)=0 \\
& \int_{-\alpha}^{\beta}\left[f(W)-1-2 a W^{2}+\frac{4}{3} b W^{3}\right] W^{3} \mathrm{~d} W=0
\end{aligned}
$$

Introducing the notation

$$
\begin{aligned}
& \int_{-\alpha}^{\beta}[f(W)-1] W^{2} \mathrm{~d} W=r_{1}, \\
& \int_{-\alpha}^{\beta}[f(W)-1] W^{3} \mathrm{~d} W=r_{2}, \\
& \int_{-\alpha}^{\beta} W^{4} \mathrm{~d} W=\mu_{1}, \\
& \int_{-\alpha}^{\beta} W^{5} \mathrm{~d} W=\mu_{2}, \\
& \int_{-\alpha}^{\beta} W^{6} \mathrm{~d} W=\mu_{3},
\end{aligned}
$$

equations (A.4) and (A.5) reduce to

$$
\begin{aligned}
& r_{1}-2 a \mu_{1}+\frac{4}{3} b \mu_{2}=0, \\
& r_{2}-2 a \mu_{2}+\frac{4}{3} b \mu_{3}=0,
\end{aligned}
$$

In vector form, the set of equations (A.6) and (A.7) are

$$
G \mathbf{h}=\mathbf{r} \text {. }
$$


If the matrix $G$ is not singular, one obtains from equation (A.8)

$$
\mathbf{h}=G^{-1} \mathbf{r} \text {. }
$$

where

$$
\begin{aligned}
& G=\left(\begin{array}{ll}
2 \mu_{1} & -\frac{4}{3} \mu_{2} \\
2 \mu_{2} & -\frac{4}{3} \mu_{3}
\end{array}\right), \\
& \mathbf{h}=\left(\begin{array}{l}
a \\
b
\end{array}\right), \quad \mathbf{r}=\left(\begin{array}{l}
r_{1} \\
r_{2}
\end{array}\right) .
\end{aligned}
$$

If $G$ is not invertible

$$
\mathbf{h}=\left(G^{T} G\right)^{-1} G^{T} \mathbf{r}
$$

knowing $G^{-1}$ and $\bar{r}$ from the hydrographic data $a$ and $b$ can be computed, as well as $B$ and $\varepsilon$. From $B$ and $\varepsilon$ the sound-speed is calculated by the equation

$$
C(Z)=C_{1}\left[1+\varepsilon\left(2 \frac{W}{B}+\exp (-2 W / B)-1\right)\right]
$$

\section{References}

Chen C T and Millero F J 1977 Speed of sound in sea water at higher pressure; J. Acoust. Soc. Am. 55 129-135

Jones R M, Georges T M and Riley J P 1985 Advances in remote sensing retrieval methods (eds) A Deepak, H E Fleming and M T Chahine (New York: Deepak Publishing)

Munk W H (1974) Sound channel in an exponentially stratified ocean with application to SOFAR; J. Acoust. Soc. Am. 55 220-226

Munk W H and Wunsch C 1979 Ocean acoustic tomography: a scheme for large scale monitoring; Deep Sea Res. A26 123-161

Munk W H and Wunsch C 1987 Bias in acoustic travel time through an ocean with adiabatic rangedependency; Geophys. Astrophys. Fluid Dynamics 39 1-24

Prasanna Kumar S, Somayajulu Y K, Ramana Murty T V and Sastry J S 1988 Acoustic variability of central Bay of Bengal for tomography; Oceanologia 26

Ramana Murty T V, Somayajulu Y K, Prasanna Kumar S and Sastry J S 1987 Computational details of canonical sound-speed profile in the ocean; Report NIO TR No. 5/87

Reiniger R F and Ros C K 1968 A method of interpolation with application to oceanographic data; Deep Sea Res. 55 185-193

Somayajulu Y K, Ramana Murty T V and Prasanna Kumar S 1985 Computation of eigen rays, sourcereceiver configuration and path lengths in tomographic layers; Report NIO TR (Classified) No. 5/85 